Pesq. Vet. Bras. 35(2):169-172, fevereiro 2015 DOI: 10.1590/S0100-736X2015000200013

\title{
Gota úrica visceral em coruja suindara (Tyto alba) de vida livre ${ }^{1}$
}

\author{
Indiara dos Santos Sales ${ }^{2}$, Carlos Henrique de Oliveira Nogueira ${ }^{2}$ \\ e Leonardo Serafim da Silveira ${ }^{2 *}$
}

\begin{abstract}
Sales I.S., Nogueira C.H.O. \& Silveira L.S. 2015. [Visceral gout in a free-living owl (Tyto alba).] Gota úrica visceral em coruja suindara (Tyto alba) de vida livre. Pesquisa Veterinária Brasileira 35(2):169-172. Setor de Morfologia e Anatomia Patológica, Laboratório de Sanidade Animal, Hospital Veterinário, Universidade Estadual do Norte Fluminense Darcy Ribeiro, Av. Alberto Lamego 2000, Campos dos Goytacazes, RJ 28013-602, Brazil. E-mail: leoseraf@uenf.br

Gout, a metabolic disease characterized by deposition of uric acid crystals in tissue, can affect reptiles, mammals and birds. We studied a postmortem case of this disease in a free-living owl (Tyto alba). The pericardium was covered a whitish thick layer adhered to the myocardium, and the liver and both kidneys showed whitish areas. The microscopic examination of the heart and hepatic tissue revealed fibrinous pericarditis and necrotizing perihepatitis. Diffuse and multifocal heterophilic inflammatory infiltrate in the renal parenchyma pulmonary congestion were also displayed. The changes found are consistent with those described in the literature for uric visceral gout in birds and may even be considered as pathognomonic lesions. This is the first report of visceral gout uric on a predator-free life in Brazil.
\end{abstract}

INDEX TERMS: Raptors, owl, Tyto alba, uric gout, crystals.

RESUMO.- A gota úrica é uma doença metabólica caracterizada pela deposição de cristais de urato e ácido úrico em tecidos do corpo, que pode acometer répteis, mamíferos e aves. Neste trabalho, relata-se um caso de achados post mortem compatíveis com gota úrica visceral em um exemplar de coruja suindara (Tyto alba) de vida livre. Macroscopicamente, o pericárdio apresentava-se completamente esbranquiçado, espesso e aderido ao miocárdio e o fígado e ambos os rins apresentavam áreas esbranquiçados sugerindo acúmulo de urato. A microscopia do tecido cardíaco e hepático revelou pericardite fibrinosa e perihepatite necrosante respectivamente. Congestão pulmonar e infiltrado inflamatório heterofílico multifocal no parênquima renal também foram visualizados. As alterações encontradas são compatíveis com as descritas na literatura para gota úrica visceral em aves, podendo até serem consideradas como lesões patognomônicas. Este é o primeiro relato de gota úrica visceral em um rapinante de vida livre no Brasil.

\footnotetext{
${ }^{1}$ Recebido em 23 de junho de 2014.

Aceito para publicação em 19 de dezembro de 2014.

${ }^{2}$ Setor de Morfologia e Anatomia Patológica (LMPA), Laboratório de Sanidade Animal, Hospital Veterinário, Universidade Estadual do Norte Fluminense Darcy Ribeiro (UENF), Av. Alberto Lamego 2000, Campos dos Goytacazes, RJ 28013-602, Brazil. *Autor para correspondência: leoseraf@ uenf.br
}

TERMOS DE INDEXAÇÃO: Aves de rapina, coruja suindara, Tyto $a l b a$, gota úrica, cristais de urato.

\section{INTRODUÇÃO}

As aves de rapina ou rapinantes são aves predadoras, mundialmente distribuídas, que possuem adaptações anatômicas para a caça, como a presença de garras curvas e afiadas nos pés, forte bico em forma de gancho e extrema acuidade visual (Pereira 2006, Joppert 2007). Os rapinantes são divididos em três ordens: Accipitriformes (águias, gaviões e abutres), Falconiformes (falcões e caracarás) e Strigiformes (corujas e mochos) sendo que no Brasil, ocorrem 47 espécies de águias e gaviões, 21 espécies de falcões e carcarás, 23 espécies de corujas e 6 espécies de urubus (CBRO 2011). Em vida livre, as aves de rapina se alimentam de uma grande variedade de espécies de vertebrados e invertebrados, exceto alguns poucos gêneros que podem eventualmente complementar essa dieta com vegetais (Pereira 2006). 0 interesse nas causas de morte de rapinantes de vida livre vem aumentando devido a um significativo declínio das populações de várias espécies, ocasionado principalmente por distúrbios antrópicos como a destruição e redução do habitat, uso de pesticidas, traumas decorrentes de colisões contra veículos, redes elétricas entre outros (Morishita et al. 1998, Wendell et al. 2002, Joppert 2007). 
A gota úrica é uma doença metabólica que pode acometer répteis, aves e mamíferos, que consiste na deposição de cristais de urato de sódio em serosas de órgãos caracterizando a gota úrica visceral ou em articulações caracterizando a gota úrica articular (Okamoto et al. 2007). Em rapinantes, essa doença foi relatada pela primeira vez em 1906 (Ward \& Slaughter 1968). 0 urato de sódio é formado a partir da ionização do ácido úrico, produto final do catabolismo de proteínas e de ácidos nucléicos (Lehninger et al. 2007). 0 depósito de cristais de urato pode ocorrer devido à falha renal na excreção do ácido úrico ou por outras condições que levem a um aumento da produção ou da concentração sanguínea de ácido úrico como o excesso de proteína na dieta, sendo que os sinais clínicos da gota nas aves são comumente inespecíficos (Okamoto et al. 2007).

Há duas formas de gota úrica nas aves, a articular caracterizada pelo acúmulo de uratos ao redor das articulações causando deformações, claudicação, relutância para caminhar, diminuição da atividade e dor e, a forma visceral cujos sinais são considerados inespecíficos, havendo acometimento característico das serosas, principalmente do pericárdio parietal e rins, além do fígado, sacos aéreos e peritônio, onde pode ser observado acúmulo de material esbranquiçado e a morte súbita nesta forma é em decorrência da falência cardíaca (Costa et al. 2012).

Não há tratamento efetivo contra a gota úrica, entretanto o protocolo terapêutico recomendado consiste na correção dos níveis protéicos da dieta para até 15\%, suplementação de vitaminas $\mathrm{E}$, A e de selênio e a utilização do alopurinol (Okamoto et al. 2007), um análogo competitivo que inibe a ação da enzima xantina oxidase fazendo com que os produtos finais do catabolismo das purinas sejam a xantina e a hipoxantina que são mais hidrossolúveis que o ácido úrico (Lehninger et al. 2007).

Considerando-se que os estudos sobre morbidade e mortalidade de rapinantes de vida livre são escassos no Brasil (Joppert 2007), o presente trabalho tem como objetivo descrever achados post mortem compatíveis com gota úrica visceral em uma coruja suindara (Tyto alba) oriunda de vida livre.

\section{MATERIAL E MÉTODOS}

Um exemplar de coruja suindara (Tyto alba), ordem Strigiformes, família Tytonidae, adulta, sexo não definido, foi levado por bombeiros ao Hospital Veterinário da Universidade Estadual do Norte Fluminense Darcy Ribeiro - UENF, onde foi atendido no Núcleo de Estudos e Pesquisas de Animais Selvagens - NEPAS. Na anamnese, os bombeiros informaram que o animal foi encontrado caído no chão, próximo a uma casa. No exame clínico de emergência, observou-se moderada letargia, intenso emagrecimento evidenciado por pouca musculatura na região peitoral ("peito em facão") e desidratação demostrada pelo aprofundamento do globo ocular. Não foram encontrados indícios de traumatismo (fraturas, hematomas). Baseado nos relatos da anamnese foi feita a administração de flunixin meglumine $(1 \mathrm{mg} / \mathrm{kg}$ ) por via intramuscular. 0 animal foi mantido em observação em recinto apropriado onde foi oferecido carne moída crua e água, os quais foram rejeitados. No dia seguinte, pela manhã, quando seriam realizados exames laboratoriais complementares, o animal foi encontrado morto.

Procedeu-se a realização da necropsia para a coleta de frag- mentos dos órgãos macroscopicamente alterados, que foram acondicionados em recipientes contendo formol tamponado neutro a $10 \%$ e encaminhados ao Laboratório de Morfologia e Patologia Animal (LMPA) no Hospital Veterinário da UENF, onde foram clivados, processados por inclusão em parafina, cortados em seções de $5 \mu \mathrm{m}$ e corados pela Hematoxilina e Eosina (HE) (Prophet et al. 1994).

\section{RESULTADOS}

Na necropsia, foram visualizadas alterações macroscópicas, compatíveis com depósito de urato, no coração, fígado, rins e pulmões. 0 pericárdio apresentava-se completamente esbranquiçado, com aspecto de "pó de giz", espesso e aderido ao miocárdio. Também foram visualizadas áreas esbranquiçadas na porção cranial do fígado e múltiplos pontos esbranquiçados em ambos os rins, ambas com características análogas ao aspecto de "pó de giz" (Fig.1). Ao corte longitudinal do coração, as câmaras internas e a musculatura apresentavam-se sem alterações. Não foram visualizadas alterações nas articulações. A vesícula biliar encontrava-se repleta de seu conteúdo, contudo sem obstrução. Não havia conteúdo estomacal. Intestinos delgado e grosso estavam aparentemente sem alterações.

A análise microscópica do tecido cardíaco revelou a presença de um delgado depósito de fibrina, e infiltrado inflamatório caracterizando pericardite fibrinosa. No tecido hepático, havia perihepatite necrosante, representada por degeneração e necrose periférica sub-capsular, infiltrado inflamatório com predominância de células mononucleares e ainda um leve edema. Congestão pulmonar difusa e infiltrado inflamatório heterofílico focal no parênquima renal também foram visualizados (Fig.2).

\section{DISCUSSÃO}

A gota úrica visceral é geralmente relatada como um achado post mortem em rapinantes. Estudo retrospectivo realizado na Universidade da Califórnia sobre a causa mortis de 409 rapinantes revelou que as doenças nutricionais ou metabólicas corresponderam a 6,1\% (25/409) das causas primárias de mortes sendo que $28 \%(7 / 25)$ dessas mortes foram atribuídas à gota úrica visceral (Morishita et al. 1998). Em um relato de gota úrica visceral em falcão (Buteo

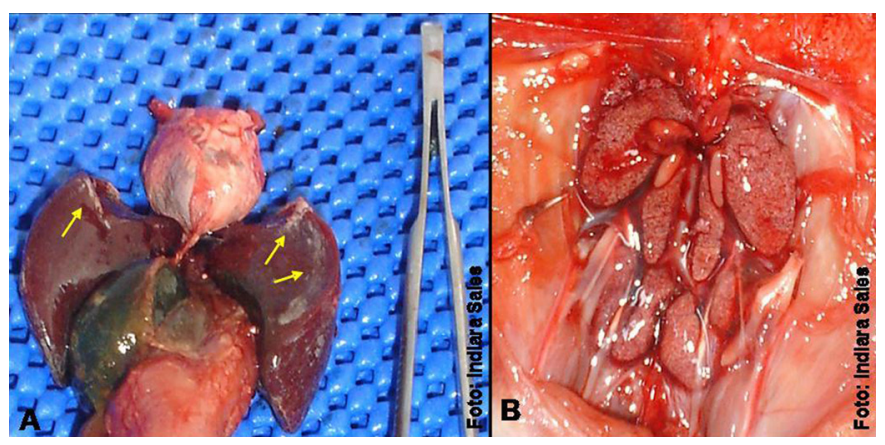

Fig.1. Alterações macroscópicas post mortem. (A) pericárdio espessado com coloração esbranquiçada (ponta de seta) fígado com manchas esbranquiçadas com aspecto de "pó de giz" (setas). (B) Rins apresentando múltiplos pontos esbranquiçados com igual característica. 


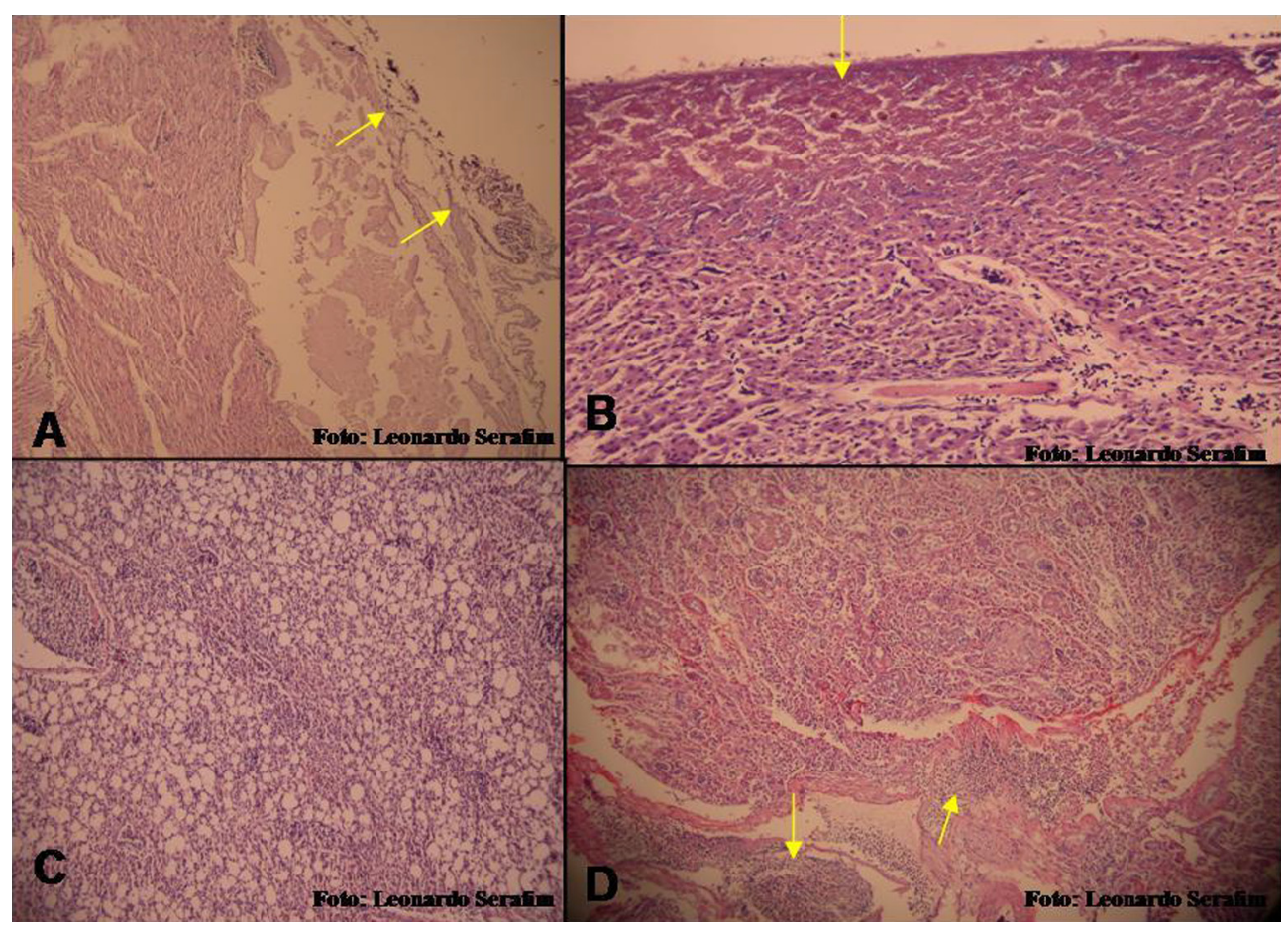

Fig.2. Alterações histológicas. (A) Pericardite fibrinosa (setas). HE, obj.4x. (B) Perihepatite necrosante (setas). HE, obj.4x. (C) Áreas difusas de congestão no tecido pulmonar. HE, obj.4x. (D) Infiltrado inflamatório heterofílico no tecido renal (setas). HE, obj.4x.

lagopus) de vida livre, os autores destacam que apesar da causa primária da morte não ter sido identificada, o comprometimento de órgãos vitais como fígado, coração e sacos aéreos pelo depósito de cristais de urato contribui para a morte do animal (Murnane \& Garner 1987), estes dados corroboram com os de nosso estudo, principalmente por se tratar de um animal de vida livre.

Uma avaliação dos níveis de ácido úrico tecidual foi realizada em um exemplar jovem de falcão de Harris $(\mathrm{Pa}$ rabuteo unicinctus) de cativeiro revelando que as concentrações de ácido úrico nos rins, musculatura esquelética e músculo cardíaco encontravam-se, respectivamente, 50 , 37 e 18 vezes maior quando comparados a tecidos de uma águia saudável (Herbert et al. 2011). Apesar de não ter sido identificado a causa do depósito de cristais de urato nesses tecidos, os autores também indicaram a gota úrica visceral como a causa da morte.

Em levantamento realizado na Austrália sobre achados mais comuns de necropsia em aves concluiu que a ocorrência de gota úrica foi maior nos rapinantes, sendo encontrada em 6\% (4/70) das aves de rapina necropsiadas (Rodney et al. 1992). Por outro lado, no Brasil, a ocorrência dessa doença não foi relatada em estudo sobre a causa da morte de 114 aves de rapina atendidas pela Divisão de Fauna do município de São Paulo entre os anos de 2002-2006 (Joppert 2007).

Além das desordens metabólicas nutricionais e consequentes patologias renais sendo incriminadas como causas da gota úrica (Poffers et al. 2002, Herbert et al. 2011), o diclofenaco e derivados também tem sido incriminado como causador desta patologia, devido à contaminação ambiental por estes fármacos, levando a altos índices de mortalidade de rapinantes de vida livre (Muralidharan \&
Dhananjayan 2010, Naidoo et al. 2011, Harris 2013), o que devemos estar atento, uma vez que estas drogas estão sendo amplamente utilizadas na medicina veterinária.

Microscopicamente, os depósitos de cristais de ácido úrico e urato apresentam-se como feixes radiados, contudo esses cristais podem ser dissolvidos quando os tecidos são fixados em formalina (Murnane \& Garner 1987), o que pode vir a corroborar com a não visualização microscópica dos cristais nas amostras teciduais analisados neste trabalho. Algumas condições inerentes ao cativeiro como dieta composta por alta quantidade de proteína e deficiência de vitaminas, e sedentarismo são descritos como fatores predisponentes para o desenvolvimento de gota úrica visceral em aves de rapina cativas (Herbert et al. 2011), contudo tratando-se de animais de vida livre, muitas vezes torna-se inviável o estabelecimento da(s) causa(s) precursoras (Wendell et al. 2002). Portanto, todas as informações geradas por estudos post mortem são de extrema importância, uma vez que permitem uma avaliação preliminar do estado de saúde da população da região do estudo, servindo de subsídio para o tratamento dos animais encaminhados para reabilitação.

Apesar de o animal ter vindo a morte antes da retirada de material para os exames complementares, as alterações macroscópicas e microscópicas encontradas são compatíveis com as descritas na literatura para gota úrica visceral em aves, podendo até serem consideradas lesões patognomônicas. Na revisão bibliográfica realizada, são encontrados relatos de gota úrica visceral e articular em aves de cativeiro, estando estas relacionadas ao erro de manejo alimentar e não foi encontrado relato de gota úrica visceral em rapinantes de vida livre no Brasil, o que torna este trabalho inédito. 


\section{REFERÊNCIAS}

CBRO 2011. Listas das Aves do Brasil. 10ª ed. Comitê Brasileiro de Registros Ornitológicos. Disponível em <http://www.cbro.org.br> Acessado em 2 ago. 2012.

Costa A.M., Imbeloni A.A., Ferreira V.L. \& Raso T.F. 2012. Gota úrica visceral em Harpia (Harpia harpyja). Nosso Clínico 15(86):60-62.

Harris J.R. 2013. The conservation of Accipitridae vultures of Nepal: a review. J. Threatened Taxa 5(2):3603-3619.

Herbert J.D., Coulson J.O. \& Coulson T.D. 2011. Quantification of tissue uric acid levels in a Harris's hawk with visceral gout: case report. Avian Dis. 55(3):513-515.

Joppert A.M. 2007. Estudo prospectivo das causas de morte de Falconiformes e Strigiformes de vida livre no município de São Paulo. Tese de Doutorado em Ciências, Faculdade de Medicina Veterinária e Zootecnia, Universidade de São Paulo, São Paulo, SP. 238p.

Lehninger A.L., Nelson D.L. \& Cox M.M. 2007. Princípios de Bioquímica. 4aㅡ ed. Sarvier, São Paulo. 1232p.

Morishita T.Y., Fullerton A.T., Lowenstine L.J., Gardner I.A. \& Brooks D.L. 1998. Morbidity and mortality in free-living raptorial birds of northern California: a retrospective study, 1983-1994. J. Avian Med. Surg. 2:78-81.

Muralidharan S. \& Dhananjayan V. 2010. Diclofenac residues in blood plasma and tissues of vultures collected from Ahmedabad, India. Bull. Environ. Contamin. Toxicol. 85(4):377-380.
Murnane R.D. \& Garner M.M. 1987. Visceral gout in a rough legged hawk (Buteo lagopus). J. Wildl. Dis. 23:515-517.

Naidoo V., Mompati K.F., Duncan N. \& Taggart M.A. 2011. The pied crow (Corvus albus) is insensitive to diclofenac at concentrations present in carrion. J. Wildl. Dis. 47(4):936-944.

Okamoto A.S., Gonçalves-Marietto G.A. \& Filho R.L.A. 2007. Gota úrica visceral em Pingüim de Magalhães: relato de caso. Nosso Clínico 56:60.

Pereira G.J.R. 2006. Falconiformes e Strigiformes, p.252-267. In: Cubas Z.S., Silva J.C.R. \& Catão-Dias J.L. (Eds), Tratado de Animais Selvagens: medicina veterinária. Roca, São Paulo. 1354p.

Poffers J., Lumeij J. T. \& Redig P.T. 2002. Investigations into the uricolytic properties of urate oxidase in a granivorous (Columba livia domestica) and in a carnivorous (Buteo jamaicensis) avian species. Avian Pathology 31:573-579.

Prophet E.B., Mills B., Arrington J.B. \& Sobín L.H. 1994. Histotechnology. Armed Forces Institute of Pathology, Washington, DC. 274p.

Rodney L., Reece V.D., Beddome D.A., Barr P.C. \& Scott S. 1992. Common necropsy findings in captive birds in Victoria, Australia (1978-1987). J. Zoo Wildl. Med. 3:301-312.

Ward F.P. \& Slaughter L.J. 1968. Visceral gout in a captive Cooper's hawk. Bull. Wildl. Dis. Assoc. 4:91-93.

Wendell M.D., Sleeman J.M. \& Kratz G. 2002. Retrospective study of morbidity and mortality of raptors admitted to Colorado state university veterinary teaching hospital during 1995 to 1998. J. Wildl. Dis. 1:101-106. 